\title{
Analyzing the Significance of T1 Slope minus Cervical Lordosis in Patients with Anterior Cervical Discectomy and Fusion Surgery
}

\author{
Ho Jin Lee, ${ }^{1}$ Soon Tae You, Jae Hoon Sung, II Sup Kim, Jae Taek Hong ${ }^{2}$ \\ Department of Neurosurgery, St. Vincent Hospital, College of Medicine, The Catholic University of Korea, Suwon, Korea \\ Department of Neurosurgery, Eunpyeong St. Mary's Hospital, College of Medicine, The Catholic University of Korea, Seoul, Korea
}

Objective : Accurate measurement of T1 slope (a component of T1s minus cervical lordosis [CL]) is often constrained by anatomical limitations. In this situation, efforts should be made to find the exact meaning of $T 1 s-C L$ and whether there are any alternatives to it.

Methods : We enrolled 117 patients who received two-level anterior cervical discectomy and fusion (ACDF). Occipital slope, C2 slope (C2s), C7 slope (C7s), T1, O-C2 angle (O-C2A), C2-7 angle (C2-7A), O-C7 angle (O-C7A), T1s-CL, C7-T1 angle (C7-T1A), and C2-7 sagittal vertical axis were measured. We determined $16^{\circ}(\mathrm{T} 1 \mathrm{~s}-\mathrm{CL})$ as the reference point for dividing subjects into the mismatch group and the balance group, and a comparative analysis was performed.

Results : The mean value of C7-T1A was constantly maintained within $2.6^{\circ}$ peri-operatively. In addition, C2s and T1s-CL showed the same absolute change $\left(\Delta|0.8|^{\circ}\right)$. The mean values of T1s-CL of the mismatch and balance groups were $23.0^{\circ}$ and $7.6^{\circ}$, respectively. The five factors with the largest differences between the two groups were as follows : $\mathrm{C} 2 \mathrm{~s}\left(\Delta 13.3^{\circ}\right), \mathrm{T} 1 \mathrm{~s}-\mathrm{CL}\left(\Delta 15.4^{\circ}\right), 0-\mathrm{C} 2 \mathrm{~A}\left(\Delta 8.7^{\circ}\right)$, C2-7A $\left(\Delta 14.7^{\circ}\right)$, and segmental angle $\left(\Delta 7.9^{\circ}\right)$ before surgery. Only four factors showed statistically significant change between the two groups after ACDF : T1s-CL $\left(\Delta 4.0^{\circ}\right.$ vs. $\left.\Delta 0.2^{\circ}\right), C 2 s\left(\Delta 3.2^{\circ}\right.$ vs. $\left.\Delta 0.7^{\circ}\right), 0-C 2 A\left(\Delta 2.6^{\circ}\right.$ vs. $\left.\Delta 1.3^{\circ}\right), C 2-7 A\left(\Delta 6.3^{\circ}\right.$ vs. $\left.\Delta 1.3^{\circ}\right)$. A very strong correlation between T1s-CL and $\mathrm{C} 2 \mathrm{~s}$ was also found $(\mathrm{r}=|0.88-0.96|)$.

Conclusion : $\mathrm{C} 2 \mathrm{~s}$ itself may be the essential key to represent T1s-CL. The amounts and directions of change of these two factors (T1s-CL and C2s) were also almost identical. The above phenomenon was re-confirmed once again through the correlation analysis.

Key Words : T1 slope · Cervical lordosis · Cervical sagittal balance · Anterior cervical discectomy and fusion · C2 slope.

\section{INTRODUCTION}

Understanding the cervical sagittal balance has always been very important to spine surgeons, due to its great influence on the clinical outcomes in cervical spine surgery. Actually, cervical balance also plays an important role in determining sur- gical strategy (surgical approach or instrumentation level) and in predicting clinical prognosis (adjacent segmental disease) after surgery ${ }^{6,717,24)}$. In line with the perception of the importance of cervical balance itself, many different radiologic factors have been proposed and evaluated for their usefulness ${ }^{16)}$.

Recently, after the concepts of the thoracic inlet angle (simi-

- Received : January 13, 2021 •Revised : March 3, 2021 •Accepted : March 3, 2021

- Address for reprints : II Sup Kim

Department of Neurosurgery, St. Vincent's Hospital, College of Medicine, The Catholic University of Korea, 93 Jungbu-daero, Paldal-gu, Suwon 16247, Korea Tel : +82-31-249-7196, Fax : +82-31-249-5208, E-mail : nsman72@hanmail.net, ORCID : https://orcid.org/0000-0001-6328-2955

This is an Open Access article distributed under the terms of the Creative Commons Attribution Non-Commercial License (http://creativecommons.org/licenses/by-nc/4.0) which permits unrestricted non-commercial use, distribution, and reproduction in any medium, provided the original work is properly cited. 
lar to pelvic incidence in the thoracolumbar spine) and $\mathrm{T} 1$ slope (T1s) had been established, another derived factor (T1s minus cervical lordosis [CL]) has also been viewed as an essential parameter ${ }^{15,25,26)}$. Although the usefulness of the above radiological parameters has been proven in many previous reports, the accurate measurement of T1s is not usually easy for many patients, due to their short necks or obstruction of shoulder shading ${ }^{22)}$. Therefore, there is a fundamental limit to the general application of these good cervical parameters to all patients. The reliable way to identify the change of spine balance and to evaluate the usefulness of a specific radiologic parameter can be determined through the cervical spine operation. Generally, anterior cervical discectomy and fusion (ACDF) is the most widely performed procedure in cervical spondylosis patient. Therefore, we aimed to define the clinical significance of T1s minus CL (T1s-CL) in the patients who underwent ACDF.

\section{MATERIALS AND METHODS}

This study was approved by the Institutional Review Board of St. Vincent Hospital, The Catholic University of Korea (VC19RISI0232).

\section{Study patients}

A retrospective analysis of radiological parameters was performed with 117 patients, who received two-level ACDF (C45-6 or C5-6-7) by two senior spine doctors (J.T.H. and I.S.K.) from January 2010 to December 2018. All cases had degenerative pathologic origins (herniation nucleus pulposus, spinal stenosis, and spondylosis) and allograft plate systems were applied to all patients. We excluded patients with prior cervical spine surgery, major trauma, infectious disease, tumor origin, and congenital deformity. Moreover, we excluded some other patients, who underwent ACDF with a stand-alone cage, anchored cage, or total disc replacement construct.

\section{Radiographic measurements}

X-ray scan of neutral cervical spine was conducted with up-
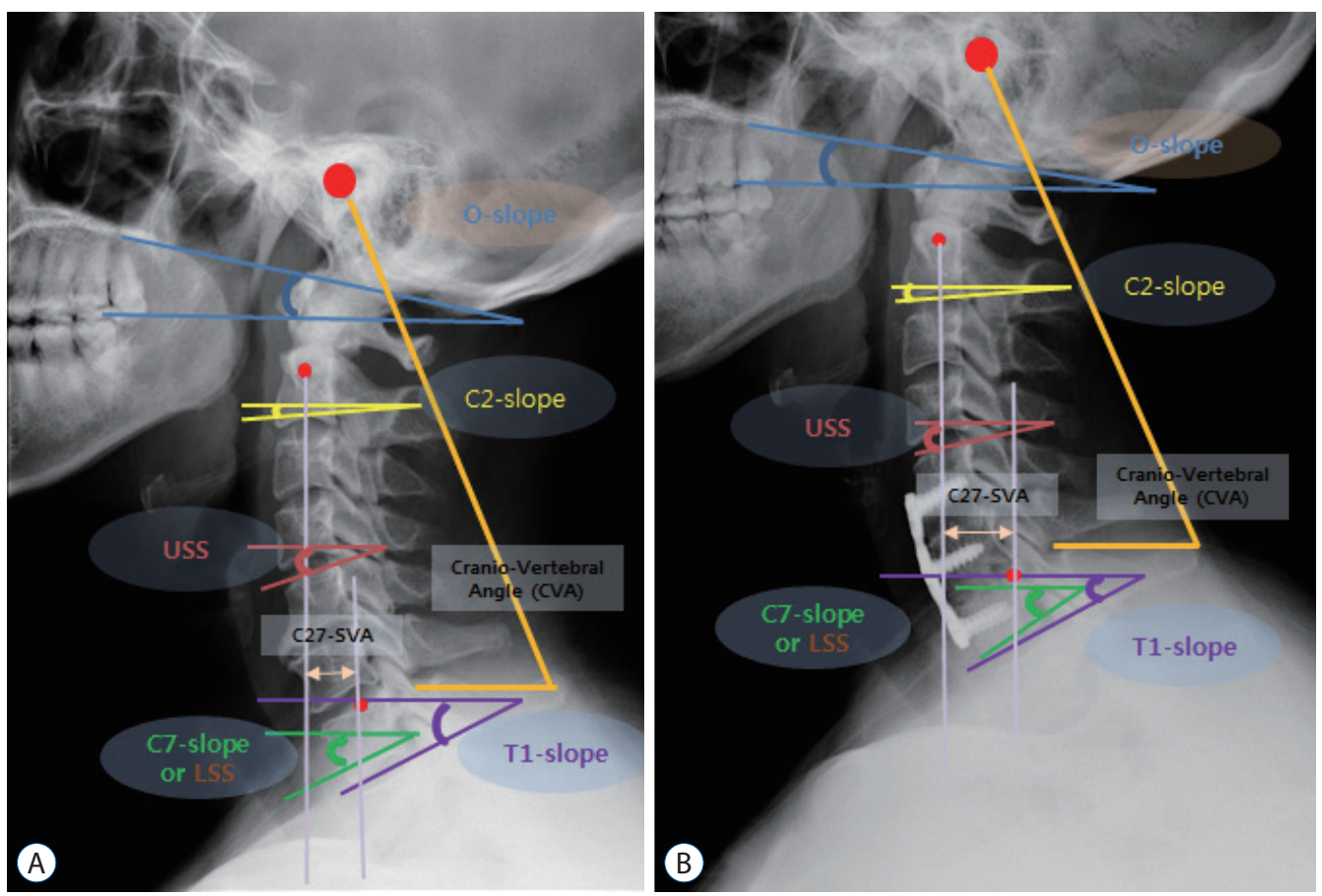

Fig. 1. Parameters measured before (A) and after surgery (B). The slope angle was measured with a horizontal line and a specific reference line at each cervical level : McGregor line (occipital slope), lower endplate of C2 body (C2 slope), lower endplate of C7 body (C7 slope), upper endplate of T1 body (T1 slope), upper segmental slope (USS), lower segmental slope (LSS). C2-7SVA (distance between the C2 plumb line and the superior posterior corner of C7 body), cranio-vertebral angle (CVA; the angle between the connecting line from the $\mathrm{EAC}$ to the distal tip of the spinous process of $\mathrm{C} 7$ and the horizontal line. 
right neutral standing position with patients receiving guidance on maintaining a comfortable straight horizontal gaze.

The radiographic parameters were the occipital slope (Os), C2 slope (C2s), C7 slope (C7s), T1s, O-C2 angle (O-C2A), C2-7 angle (C2-7A), O-C7 angle (O-C7A), T1s-CL, craniovertebral angle (CVA; the angle between the connecting line from the external auditory canal to the distal tip of the spinous process of $\mathrm{C} 7$ and the horizontal line), upper segmental slope (USS), lower segmental slope (LSS), segmental angle (SA), and C2-7 sagittal vertical axis (C2-7SVA; distance between the $\mathrm{C} 2$ plumb line and the superior posterior corner of C7 body), and these were measured pre- and postoperatively (Fig. 1). The slope angle was basically measured with a horizontal line and a specific reference line at each cervical level : McGregor line (Os), lower endplate of C2 body (C2s), lower endplate of $\mathrm{C} 7$ body (C7s), upper endplate of $\mathrm{T} 1$ body (T1s), upper endplate of C4 body (C4USS, ACDF C4-5-6), upper endplate of C5 body (C5USS, ACDF C5-6-7), lower endplate of C6 body (C6LSS, ACDF C4-5-6), and lower endplate of C7 body (C7LSS, ACDF C5-6-7). The angular values were calculated with two different slope lines: O-C2A (Os and C2s), C27A (C2s and C7s), O-C7A (Os and C7s), SA (USS and LSS), and T1s-CL (T1s minus C2-7A).

All radiological measurements were conducted with a picture archiving and communication system (m-view 5.4.; Marosis Technologies, Inc., Seoul, Korea). The slope angle was positive when the specific line was oriented upward from the horizontal line, and lordosis was defined as a positive value. The difference in values before and after surgery was denoted as $\Delta$ for each radiologic parameter. We conducted sub-group analysis according to the pre-operative state of T1s-CL, and we subdivided all patients into two different groups (the mismatch group and the balance group). We used 16 degrees (T1s-CL) as the reference point for dividing cases into the Mismatch group and Balance group.

\section{Statistics}

We performed statistical analyses using the Wilcoxon signed rank test or paired t-test, unpaired t-test, and Pearson correlation analysis using SAS ver. 9.4 (SAS Institute INC., Cary, NC, USA) in this study. Statistical significance was set at $p \leq 0.05$.

\section{RESULTS}

\section{Whole patients}

The mean patient age was $55.8 \pm 8.5$ (range, 32 to 80 ) years old, and there were 65 men and 52 women. The distribution of fusion index levels was 53 patients at C4-5-6 and 62 patients at C5-6-7.

Almost every value of the changes in sagittal parameters

Table 1. Changes in radiological parameter values before and after two-level anterior cervical discectomy and fusion

\begin{tabular}{|c|c|c|c|c|}
\hline Variable & Pre-operation & Post-operation & Difference value $(\Delta)$ & $p$-value \\
\hline Occipital slope $\left(^{\circ}\right)$ & $7.2 \pm 6.1$ & $6.7 \pm 5.5$ & -0.5 & 0.36 \\
\hline C2 slope $\left(^{\circ}\right)$ & $-9.7 \pm 9.0$ & $-8.9 \pm 7.6$ & 0.8 & 0.18 \\
\hline C7 slope $\left(^{\circ}\right)$ & $-19.9 \pm 7.5$ & $-21.7 \pm 8.1$ & -1.8 & $<0.01$ \\
\hline T1 slope $\left(^{\circ}\right)$ & $-22.4 \pm 7.4$ & $-24.3 \pm 7.9$ & -1.9 & $<0.001$ \\
\hline $\mathrm{T} 1 \mathrm{~s}-\mathrm{CL}\left({ }^{\circ}\right)$ & $11.9 \pm 9.4$ & $10.7 \pm 9.3$ & -0.8 & 0.54 \\
\hline $\mathrm{O}-\mathrm{C} 2$ angle $\left(^{\circ}\right)$ & $16.9 \pm 9.0$ & $15.6 \pm 7.2$ & -1.3 & $<0.01$ \\
\hline C2-7 angle $\left(^{\circ}\right)$ & $10.4 \pm 10.9$ & $12.7 \pm 10.6$ & 2.3 & $<0.01$ \\
\hline $\mathrm{O}-\mathrm{C} 7$ angle $\left(^{\circ}\right)$ & $27.0 \pm 9.3$ & $28.2 \pm 9.0$ & 1.2 & 0.12 \\
\hline Segmental slope, upper $\left(^{\circ}\right)$ & $-15.0 \pm 6.6$ & $-13.5 \pm 6.3$ & 1.5 & $<0.01$ \\
\hline Segmental slope, lower $\left(^{\circ}\right)$ & $-18.1 \pm 8.1$ & $-19.8 \pm 8.4$ & -1.7 & $<0.01$ \\
\hline Segmental angle $\left(^{\circ}\right)$ & $3.1 \pm 7.4$ & $6.4 \pm 7.0$ & 3.3 & $<0.001$ \\
\hline Cranio-vertebral angle $\left(^{\circ}\right)$ & $63.5 \pm 5.7$ & $61.3 \pm 13.4$ & -2.2 & $<0.05$ \\
\hline C2-7 sagittal vertical axis (mm) & $18.8 \pm 12.1$ & $19.5 \pm 11.7$ & 0.7 & 0.41 \\
\hline
\end{tabular}

Values are presented as mean \pm standard deviation or number. $\mathrm{T} 1 \mathrm{~s}-\mathrm{CL}: \mathrm{T} 1$ slope minus cervical lordosis 
was less than $3.3^{\circ}\left(\Delta \mathrm{SA}, 3.3^{\circ} ; \Delta \mathrm{C} 2-7 \mathrm{~A}, 2.6^{\circ} ; \Delta \mathrm{C} 7 \mathrm{~s}, 1.8^{\circ} ; \Delta \mathrm{C} 7 \mathrm{~s}\right.$, $1.8^{\circ} ; \Delta \mathrm{T} 1 \mathrm{~s}, 1.8^{\circ} ; \Delta \mathrm{O}-\mathrm{C} 7 \mathrm{~A}, 1.2^{\circ} ; \Delta \mathrm{O}-\mathrm{C} 2 \mathrm{~A}, 1.3^{\circ}$; and $\Delta \mathrm{CVA}$, $1.7^{\circ}$ ), and $\triangle \mathrm{C} 2-7 \mathrm{SVA}$ was $0.7 \mathrm{~mm}$ after 2-level ACDF in whole patients (Table 1). All parameters related to the surgical index level (USS, LSS, and SA) were changed at a statistically significant level, and all lower cervical parameters (C7s and T1s) also showed statistically significant changes after ACDF. Although the upper cervical angle (O-C2A) and lower cervical angle $(\mathrm{C} 2-7 \mathrm{~A})$ were significantly changed, the whole cervical angle (O-C7A) was not statistically different $(p=0.12)$. The C2s, T1s$\mathrm{CL}$, and C2-7SVA values did not show significant changes after the operation.

Table 2. The difference in sagittal balance between the mismatch and the balance groups in the pre-operative state

\begin{tabular}{|c|c|c|c|c|}
\hline Pre-operation & Mismatch group & Balance group & Difference value $(\Delta)$ & $p$-value \\
\hline Occipital slope $\left(^{\circ}\right)$ & $2.9 \pm 4.6$ & $7.4 \pm 5.4$ & 4.5 & $<0.01$ \\
\hline C2 slope $\left({ }^{\circ}\right)$ & $-19.1 \pm 4.6$ & $-5.8 \pm 6.5$ & 13.3 & $<0.01$ \\
\hline C7 slope $\left(^{\circ}\right)$ & $-20.1 \pm 8.3$ & $-21.4 \pm 8.2$ & -1.3 & 0.74 \\
\hline T1 slope $\left({ }^{\circ}\right)$ & $-23.9 \pm 7.3$ & $-23.6 \pm 8.1$ & 0.6 & 0.20 \\
\hline $\mathrm{T} 1 \mathrm{~s}-\mathrm{CL}\left({ }^{\circ}\right)$ & $23.0 \pm 5.7$ & $7.6 \pm 6.9$ & -15.4 & $<0.01$ \\
\hline O-C2 angle $\left(^{\circ}\right)$ & $22.0 \pm 6.0$ & $13.3 \pm 7.0$ & -8.7 & $<0.01$ \\
\hline C2-7 angle $\left(^{\circ}\right)$ & $1.0 \pm 9.4$ & $15.7 \pm 10.1$ & 14.7 & $<0.01$ \\
\hline $\mathrm{O}-\mathrm{C} 7$ angle $\left(^{\circ}\right)$ & $23.0 \pm 9.5$ & $28.8 \pm 9.2$ & 5.8 & $<0.05$ \\
\hline Segmental slope, upper $\left({ }^{\circ}\right)$ & $-18.4 \pm 5.8$ & $-13.0 \pm 5.8$ & 5.4 & $<0.01$ \\
\hline Segmental slope, lower $\left(^{\circ}\right)$ & $-17.7 \pm 8.8$ & $-19.8 \pm 8.7$ & -2.1 & 0.90 \\
\hline Segmental angle $\left(^{\circ}\right)$ & $-0.9 \pm 7.6$ & $7.0 \pm 7.2$ & 7.9 & $<0.01$ \\
\hline Cranio-vertebral angle $\left({ }^{\circ}\right)$ & $59.5 \pm 4.2$ & $62.0 \pm 16.6$ & 2.5 & $<0.01$ \\
\hline C2-7SVA (mm) & $26.2 \pm 9.6$ & $15.6 \pm 8.9$ & -11.6 & $<0.01$ \\
\hline
\end{tabular}

Values are presented as mean \pm standard deviation or number. T1s-CL : T1 slope minus cervical lordosis, C2-7SVA : C2-7 sagittal vertical axis

Table 3. The measured value of each parameter in the mismatch and balance groups

\begin{tabular}{|c|c|c|c|c|c|c|c|}
\hline \multirow{2}{*}{ Variable } & \multicolumn{3}{|c|}{ Mismatch group } & \multicolumn{3}{|c|}{ Balance group } & \multirow{2}{*}{$\begin{array}{c}p \text {-value } \\
\left(\Delta^{1} \text { vs. } \Delta^{2}\right.\end{array}$} \\
\hline & Pre-OP & Post-OP & $\Delta^{1} / p$-value & Pre-OP & Post-OP & $\Delta^{2} / p$-value & \\
\hline Occipital slope $\left(^{\circ}\right)$ & $2.9 \pm 4.6$ & $3.5 \pm 4.6$ & $0.6 / 0.98$ & $8.3 \pm 5.7$ & $7.4 \pm 5.4$ & $-0.9 / 0.48$ & 0.58 \\
\hline C2 slope $\left(^{\circ}\right)$ & $-19.1 \pm 4.6$ & $-15.9 \pm 6.1$ & $3.2 /<0.01$ & $-5.1 \pm 6.3$ & $-5.8 \pm 6.5$ & $-0.7 / 0.62$ & $<0.01$ \\
\hline C7 slope $\left(^{\circ}\right)$ & $-20.1 \pm 8.3$ & $-23.2 \pm 9.3$ & $-3.1 /<0.05$ & $-19.5 \pm 7.6$ & $-21.4 \pm 8.2$ & $-1.9 /<0.01$ & 0.40 \\
\hline T1 slope $\left({ }^{\circ}\right)$ & $-23.9 \pm 7.3$ & $-26.3 \pm 8.3$ & $-2.4 /<0.05$ & $-21.8 \pm 7.4$ & $-23.6 \pm 8.1$ & $-1.8 /<0.01$ & 0.80 \\
\hline $\mathrm{T} 1 \mathrm{~s}-\mathrm{CL}\left({ }^{\circ}\right)$ & $23.0 \pm 5.7$ & $19.0 \pm 9.0$ & $-4.0 /<0.05$ & $7.4 \pm 6.4$ & $7.6 \pm 6.9$ & $-0.2 / 0.51$ & $<0.05$ \\
\hline O-C2 angle $\left(^{\circ}\right)$ & $22.0 \pm 6.0$ & $19.4 \pm 6.3$ & $-2.6 /<0.01$ & $13.5 \pm 8.2$ & $13.3 \pm 7.0$ & $0.2 / 0.47$ & $<0.05$ \\
\hline C2-7 angle $\left(^{\circ}\right)$ & $1.0 \pm 9.4$ & $7.3 \pm 11.7$ & $6.3 /<0.05$ & $14.4 \pm 9.9$ & $15.7 \pm 10.1$ & $1.3 / 0.10$ & $<0.05$ \\
\hline $\mathrm{O}-\mathrm{C} 7$ angle $\left(^{\circ}\right)$ & $23.0 \pm 9.5$ & $26.7 \pm 9.9$ & $3.7 / 0.08$ & $27.9 \pm 9.1$ & $28.8 \pm 9.2$ & $0.9 / 0.14$ & 0.27 \\
\hline Segmental slope, upper $\left({ }^{\circ}\right)$ & $-18.4 \pm 5.8$ & $-16.3 \pm 6.6$ & $2.1 /<0.05$ & $-13.4 \pm 5.5$ & $-13.0 \pm 5.8$ & $0.4 / 0.50$ & 0.11 \\
\hline Segmental slope, lower $\left(^{\circ}\right)$ & $-17.7 \pm 8.8$ & $-20.8 \pm 9.3$ & $-3.1 /<0.05$ & $-17.6 \pm 7.9$ & $-19.8 \pm 8.7$ & $-2.2 /<0.01$ & 0.66 \\
\hline Segmental angle $\left(^{\circ}\right)$ & $-0.9 \pm 7.6$ & $4.5 \pm 7.6$ & $5.4 /<0.01$ & $4.1 \pm 7.4$ & $7.0 \pm 7.2$ & $2.9 /<0.05$ & 0.20 \\
\hline CVA $\left(^{\circ}\right)$ & $59.5 \pm 4.2$ & $59.3 \pm 5.1$ & $-0.2 / 0.78$ & $65.3 \pm 4.9$ & $62.0 \pm 16.6$ & $-3.3 /<0.05$ & 0.31 \\
\hline C2-7SVA $\left({ }^{\circ}\right)$ & $26.2 \pm 9.6$ & $25.6 \pm 11.5$ & $-0.6 / 0.48$ & $14.6 \pm 8.4$ & $15.6 \pm 8.9$ & $1.0 / 0.24$ & 0.16 \\
\hline
\end{tabular}

Values are presented as mean \pm standard deviation unless otherwise indicated. OP : operation, T1s-CL : T1 slope minus cervical lordosis, CVA : craniovertebral angel, C2-7SVA : C2-7 sagittal vertical axis 


\section{Sub-group analysis}

Table 2 shows the differences in sagittal balance between the mismatch and balance groups before surgery. The mean difference values between the two groups were as follows : Os $\left(\Delta 4.5^{\circ}\right)$, C2s $\left(\Delta 13.3^{\circ}\right)$, T1s-CL $\left(\Delta 15.4^{\circ}\right)$, O-C2A $\left(\Delta 8.7^{\circ}\right)$, C2$7 \mathrm{~A}\left(\Delta 14.7^{\circ}\right)$, O-C7A $\left(\Delta 5.8^{\circ}\right)$, USA $\left(\Delta 5.4^{\circ}\right)$, SA $\left(\Delta 7.9^{\circ}\right)$, CVA $\left(\Delta 2.5^{\circ}\right)$, and C2-7SVA $(\Delta 11.6 \mathrm{~mm})$. Two lower cervical slopes (C7s and T1s) and LSS were not statistically different between the two groups.

After surgery, the change of cervical sagittal parameters was much different between the mismatch and balance groups (Table 3). The change values of most factors were much bigger in the mismatch group than in the balanced group : T1s-CL $\left(\Delta 4.0^{\circ}\right.$ vs. $\left.\Delta 0.2^{\circ}\right), \mathrm{C} 2 \mathrm{~s}\left(\Delta 3.2^{\circ}\right.$ vs. $\left.\Delta 0.7^{\circ}\right)$, O-C2A $\left(\Delta 2.6^{\circ}\right.$ vs. $\left.\Delta 1.3^{\circ}\right)$, C2-7A $\left(\Delta 6.3^{\circ}\right.$ vs. $\left.\Delta 1.3^{\circ}\right)$, USS $\left(\Delta 2.1^{\circ}\right.$ vs. $\left.\Delta 0.4^{\circ}\right)$, LSS $\left(\Delta 3.1^{\circ}\right.$ vs. $\left.\Delta 2.2^{\circ}\right)$, and SA $\left(\Delta 5.4^{\circ}\right.$ vs. $\left.\Delta 2.9^{\circ}\right)$. Although the changes in C7s and T1s were statistically significant in both groups, the absolute difference value was much larger in the mismatch group (C7s: $\Delta 3.1^{\circ}$ vs. $\Delta 1.9^{\circ}$ and Tls: $\Delta 2.4^{\circ}$ vs. $\Delta 1.8^{\circ}$ ). Only the change in CVA $\left(0.2^{\circ}\right.$ vs. $\left.3.3^{\circ}\right)$ was much bigger in the Balance group than in the Mismatch group. Only four parameters (C2s, T1s-CL, O-C2A, and C2-7A) showed the statistically significant changes between the two groups after surgery.

\section{Correlation analysis}

Table 4 shows calculated correlation scores between the five important radiological factors (C2s, T1s-CL, C2-7A, T1s, and C7s) and all the other radiological factors before and after surgery. Overall, most factors maintained similar statistical correlations before and after surgery, except for CVA. C2s and T1s-CL showed very similar correlation patterns and scores with all other radiological factors and very high correlation scores ( $\mathrm{r}=-0.96$ and $\mathrm{r}=-0.88$ ) with each other. These two factors were statistically correlated with Os, O-C2A, C2-7A, USS, SA, CVA, and C2-7SVA, but did not show statistical correlation with the other three factors (C2s, C7s, and LSS) peri-operatively. C2-7A was statistically correlated with all $(\mathrm{r}=\mid 0.20$ $0.71 \mid$ ) but one factor (USA, $r=0.13$ ) before surgery. However, three other factors (Os, CVA, and C2-7SVA) did not show statistical correlation with C2-7A after surgery. C7s and T1s also showed very similar correlation patterns and scores with all other radiological factors and very high correlation scores $(r=0.91$ and $r=0.94)$ with each other. Two lower cervical parameters (C7s and T1s) were statistically correlated with C2-7A,

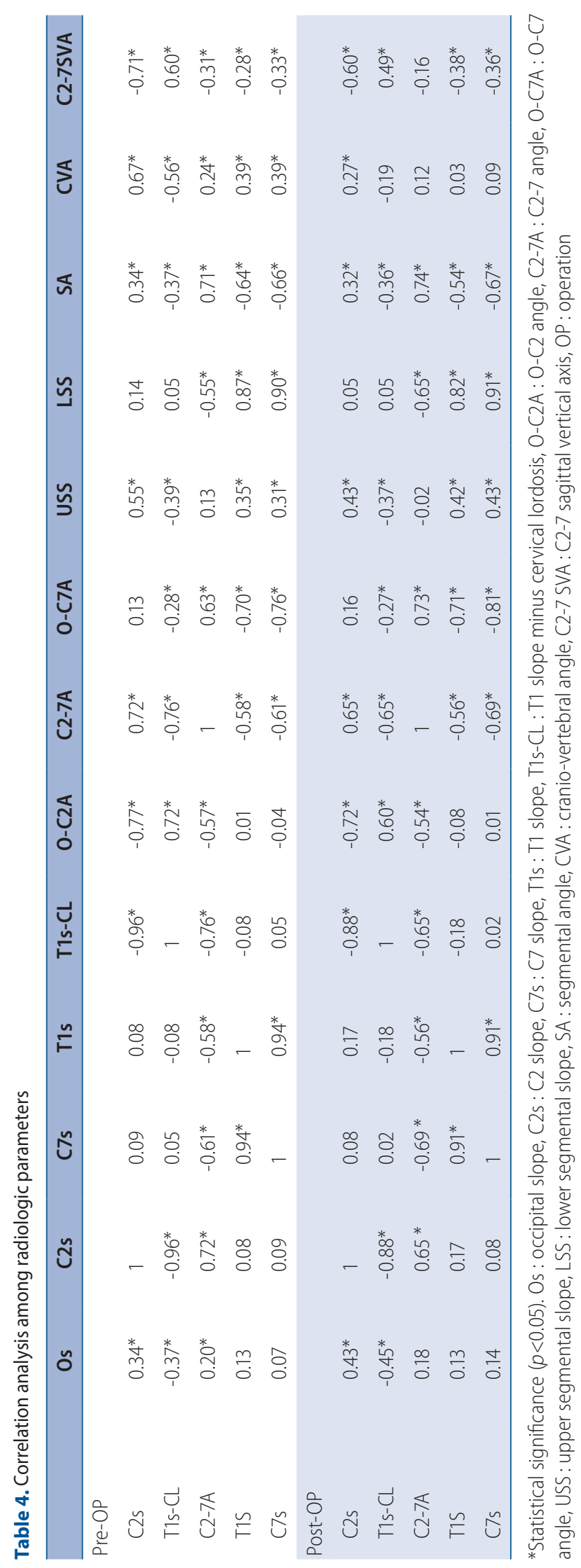


O-C7A, USS, LSS, SA, and C2-7SVA. However, these factors were not correlated with upper cervical parameters (Os, C2s, and $\mathrm{O}-\mathrm{C} 2 \mathrm{~A}$ ) and T1s-CL peri-operatively.

\section{DISCUSSION}

The ideal approach for the evaluation of cervical sagittal alignment may be through major cervical deformity patients; however, these cases are very rare compared to thoracolumbar deformity cases ${ }^{4,19,21,23)}$. Therefore, we assumed that the next best thing is to evaluate sagittal alignment with the most widely used procedure and disease. As we know, ACDF is the most common and widely performed procedure for cervical spondylosis. Recently, some previous reports have been published for the same purposes as ours, and the results showed that ACDF can influence the change of spine alignment regionally (cervical spine) or globally (whole spine) ${ }^{8,9)}$. Moreover, as described in our previous report $(n=61$, conducted at a different institution), the cervical alignment change after ACDF was variable and dependent on whether or not pre-operative segmental kyphosis existed ${ }^{10)}$.

Previous studies also revealed some important factors about sagittal balance analysis. First, the use of a plate construct may induce better sagittal alignment change than using a cagealone technique. Second, more obvious sagittal alignment changes occur in two-level ACDF than in one-level ACDF ${ }^{3,11}$. In an effort to leverage the above phenomenon, we selectively conducted our study with two-level ACDF and only with procedures using a plate (allobone spacer) system to maintain consistency of biomechanical effects ${ }^{20)}$.

In the present study, two-level ACDF induced statistically significant changes of many radiological factors $(\mathrm{C} 7 \mathrm{~s}, \mathrm{~T} 1 \mathrm{~s}$, O-C2A, C2-7A, USS, LSS, SA, and CVA). However, other factors (Os, C2s, T1s-CL, O-C7A, and C2-7SVA) did not show significant changes after ACDF. Although correlation analysis may be more precise to estimate the relationships among many radiological factors, the grasp of directional or numerical changes of each parameter can also give us some clues to estimate relationships between specific parameters. From this point of view, the directions and numerical changes between C7s and T1s were very similar $\left(\Delta-1.8^{\circ}\right.$ vs. $\left.\Delta-1.9^{\circ}\right)$, and $\mathrm{C} 2 \mathrm{~s}$ and
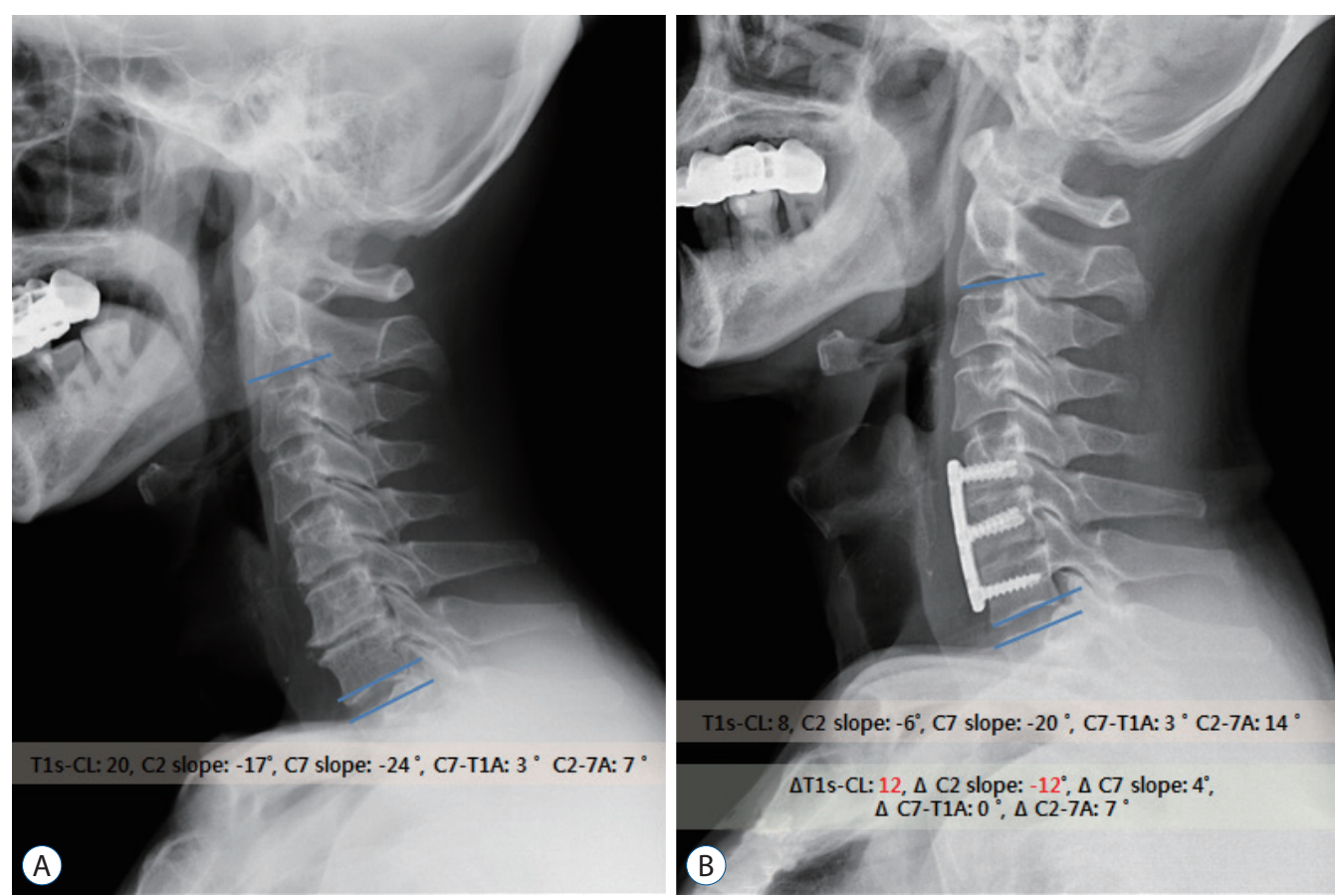

Fig. 2. Example of sagittal alignment changes after $A C D F(A$ and $B)$ in mismatch group patients (T1s-CL, 20). Two levels $A C D F$ induced improvement of cervical lordosis (C2-7A) and T1s-CL (20 $\rightarrow 8)$. Because, C7-T1A remained constant with a small difference $\left(3^{\circ}\right)$, the difference value between T1s-CL and C2 slope was also maintained constantly. ACDF : anterior cervical discectomy and fusion, T1s-CL : T1 slope minus cervical lordosis, C2-7A : C2-7 angle, C7T1A: C7-T1 angle. 
T1s-CL also showed the same absolute change value $\left(\Delta|0.8|^{\circ}\right)$. Like our previous report, there was a close association in directional nature between T1s and C7s and these two parameters did not significantly differ in some previous reports ${ }^{1,14}$.

T1s-CL has been recognized as an important factor, which might affect cervical balance and clinical symptoms ${ }^{12}$. Some previous papers insisted not to exceed a certain T1s-CL value $\left(14.5^{\circ}-26.5^{\circ}\right)$ to prevent malalignment and the worsening of clinical results. Moreover, some other reports showed the normal value of T1s-CL from $15.8^{\circ}$ to $22.2^{\circ 2,5,18,21)}$. Therefore, we selected $16^{\circ}$ as the reference value of T1s-CL for dividing patients into two groups (mismatch group : $23.0^{\circ}$ vs. balance group : $7.6^{\circ}$ ) in this study, as most patients did not show any major deformity ${ }^{21)}$.

When we compared the two groups (mismatch vs. balance), there were statistically significant differences in most factors, excepting three radiological factors (C7s, T1s, and LSS). Anatomically, LSS was measured in the lower cervical vertebrae (C6 or C7), so the difference in lower cervical slopes may not be a decisive element of mismatch. Rather, the factor with the large difference value between the two groups may be the definite one in determining a mismatch. Therefore, we came to the conclusion that $\mathrm{C} 2\left(\Delta 13.3^{\circ}\right)$ and $\mathrm{C} 2-7 \mathrm{~A}\left(\Delta 14.7^{\circ}\right)$ should be the most decisive factors for representing a mismatch. Moreover, since the value of $\mathrm{C} 2-7 \mathrm{~A}$ is obtained by the difference value between C2s (significantly different between the two groups) and C7s (insignificantly different between the two groups), C2s will ultimately be the most important factor.

We tried to prove the above phenomenon analytically and interpreted the T1s-CL formula as below. Because usually T1s and $\mathrm{C} 7 \mathrm{~s}$ are represented as negative values in this study, the T1s-CL formula can be interpreted as |T1s|-(C2s-C7s) or |T1s|$\mathrm{C} 2 \mathrm{~s}+\mathrm{C} 7 \mathrm{~s}$. As a result, T1s-CL value is determined by two factors (C2s and C7-T1 angle [C7-T1A]). At this stage, it should be necessary to understand the aspect of the C7-T1A. The mean difference value of C7-T1A was less than $2.6^{\circ}$ and was maintained constantly pre- and postoperatively in this study. Moreover, only seven patients (7/117, 5.9\%) had a C7-T1A greater than $6^{\circ}$ before surgery. If we consider that C7-T1A was a constant value (about $3^{\circ}$ ) in most patients, the most influential factor in determining sagittal mismatch will be $\mathrm{C} 2$ itself (Fig. 2).

The patterns of change between the two groups after the ACDF procedure were very different. ACDF induced upward movement of C2s $\left(\Delta 3.2^{\circ}\right)$ and downward movement of C7s $\left(\Delta 3.1^{\circ}\right)$; thus, CL was much improved in the mismatch group. Two segmental factors (USS : $\Delta 2.1^{\circ}$ and LSS : $\Delta-3.1^{\circ}$ ) also showed similar change patterns. However, in contrast to the mismatch group, upward movement of C2s or USS did not occur in the balance group. We can also observe the smaller downward movement of C7s and LSS $\left(\Delta-1.9^{\circ}\right.$ and $\left.\Delta-2.2^{\circ}\right)$ in the balance group. Although the ACDF procedure itself has enough ability to correct regional or overall cervical deformity, the alignment change after ACDF was not very influential to well-balanced patients. The above results are in line with our previous study ${ }^{10)}$.

In addition, looking at the change between the pre- and post-operative differences between the two groups, only four factors (C2s, T1s-CL, O-C2A, and C2-7A) showed statistical significance. If we think about $\mathrm{C} 2 \mathrm{~s}$ again, the other three factors (T1s-CL, O-C2A, and C2-7A) are closely related to C2s. As we said earlier, T1s-CL can be represented as $\mathrm{C} 2 \mathrm{~s}$, and the other cervical angles (O-C2A and C2-7A) were fundamentally measured with $\mathrm{C} 2 \mathrm{~s}$. As a result, all changes of sagittal alignment may be related to $\mathrm{C} 2 \mathrm{~s}$ and represented as changes in C2s.

The close relationship between T1s-CL and C2s can be also confirmed by Pearson correlation analysis ( $\mathrm{r}=-0.96$ before surgery; $r=0.88$ after surgery). Moreover, these two factors showed very similar relationship patterns with other radiolog-

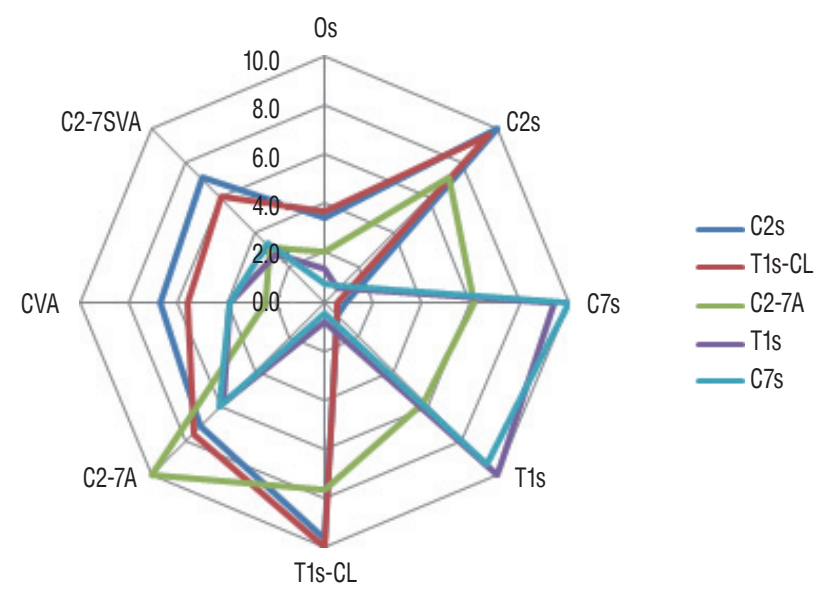

Fig. 3. This figure shows that the degree and trend of correlation among variable cervical radiologic parameters (occipital slope [Os], C2 slope [C2s], C7 slope [C7s], T1 slope [T1s], T1 slope minus cervical lordosis [T1s$\mathrm{CL}]$, C2-7 angle [C2-7A], cranio-vertebral angle [CVA], C2-7 sagittal vertical axis [C2-7SVA]) in Table 4 (pre-operation). T1s-CL and C2s have very similar degrees and trends of correlation with other parameters and C7s and T1s also show very similar patterns of correlation. 
ical factors. First, C2 and T1s-CL were not statistically related to the lower cervical slopes (C7s, T1s, and LSS). Some previous reports have also demonstrated that there is no significant correlation between T1s and T1s-CL ${ }^{21)}$. This is because, as explained earlier, T1s-CL is just a representation of C2s. Second, $\mathrm{C} 2$ and T1s-CL $(\mathrm{r}=|0.60-0.71|)$ are more closely related to the SVA than are the other three factors (C2-C7A, C7s, and T1s, $\mathrm{r}=|0.28-0.31|)$. Generally, C2-7SVA is recognized as an important indication of clinical and radiological malalignment; therefore, it is very important to identify the most relevant factors to the SVA. Kwon et al. ${ }^{11)}$ showed that SVA after twolevel ACDF was affected more significantly by C2-7A than T1s. The above result is very similar to our present result. Third, these two factors (C2 and T1s-CL) did not statistically correlate to the lower cervical slopes (C7s and T1s). In other words, the lower cervical slopes (C7s and T1s) were independent of the upper cervical slopes (C2s or Os) but were closely related to each other $(\mathrm{r}=0.91-0.94)$.

Through the correlation analysis, we found that C2-7A is most widely associated with many other radiological factors (Fig. 3). This is because the C2s reflects the upper cervical segment (Os and T1s-CL) and the C7s reflects the lower cervical segment (LSS and T1s). Therefore, measuring two absolute parameters (C2s and C7s) separately will help us to understand the overall cervical sagittal balance, rather than measuring C2-7A (relative parameter) using Cobb's method.

Our study has three limitations. First, the present study did not include clinical data that can be used to estimate the influence of sagittal balance on clinical symptoms. We assumed that the clinical outcome of ACDF may depend on the well nerve decompression rather than the cervical balance itself, as described in other reports ${ }^{11,13,24)}$. Second, we did not include cases involving C7-T1 level, which might significantly change C7-T1A. At this time, there were very few cases involving C7T1; however, further analysis of the C6-7-T1 ACDF will be meaningful. Third, we also need to see if the present findings will be consistent with the posterior cervical operation.

\section{CONCLUSION}

Generally, the incidence of major deformity pathology is very low; therefore, it may be unreasonable to apply ambiguous (T1-related) parameters to minor or relatively well-bal- anced cervical pathology routinely. Through the actual clinical analysis and arithmetical interpretation of formulas, we can conclude that the T1s-CL may just represent the C2s. However, C2s has little correlation with lower cervical parameters (C7s and T1s). Therefore, if we can recognize C7s as a substitute for T1s, just measuring C2s and C7s will give us a good guideline for understanding the overall cervical balance in ACDF patients. These two parameters (C2s and C7s) should be more easily measurable than T1-related parameters for estimating cervical sagittal balance.

\section{CONFLICTS OF INTEREST}

Jae Hoon Sung has been editorial board of JKNS since November 2016. He was not involved in the review process of this original article. No potential conf lict of interest relevant to this article was reported.

\section{INFORMED CONSENT}

This type of study does not require informed consent.

\section{AUTHOR CONTRIBUTIONS}

\author{
Conceptualization : HJL, ISK \\ Data curation : HJL, STY \\ Formal analysis : HJL, ISK \\ Methodology : JTH, HJL \\ Project administration : JHS \\ Visualization : HJL \\ Writing - original draft : HJL \\ Writing - review \& editing : HJL, ISK
}

\section{ORCID}

$\begin{array}{ll}\text { Ho Jin Lee } & \text { https://orcid.org/0000-0002-9208-5931 } \\ \text { Soon Tae You } & \text { https://orcid.org/0000-0002-0681-1774 } \\ \text { Jae Hoon Sung } & \text { https://orcid.org/0000-0003-3738-6413 } \\ \text { Il Sup Kim } & \text { https://orcid.org/0000-0001-6328-2955 } \\ \text { Jae Taek Hong } & \text { https://orcid.org/0000-0001-6453-0439 }\end{array}$




\section{References}

1. Ajello M, Marengo N, Pilloni G, Penner F, Vercelli G, Pecoraro F, et al. : Is it possible to evaluate the ideal cervical alignment for each patient needing surgery? An easy rule to determine the appropriate crvical lordosis in preoperative planning. World Neurosurg 97 : 471-478, 2017

2. Diebo BG, Challier V, Henry JK, Oren JH, Spiegel MA, Vira S, et al. : Predicting cervical alignment required to maintain horizontal gaze based on global spinal alignment. Spine (Phila Pa 1976) 41 : 1795-1800, 2016

3. Gillis CC, Kaszuba MC, Traynelis VC : Cervical radiographic parameters in 1- and 2-level anterior cervical discectomy and fusion. J Neurosurg Spine 25 : 421-429, 2016

4. Ha Y, Schwab F, Lafage V, Mundis G, Shaffrey C, Smith J, et al. : Reciprocal changes in cervical spine alignment after corrective thoracolumbar deformity surgery. Eur Spine J 23 : 552-559, 2014

5. Hyun SJ, Kim KJ, Jahng TA, Kim HJ : Relationship between T1 slope and cervical alignment following multilevel posterior cervical fusion surgery: impact of T1 slope minus cervical lordosis. Spine (Phila Pa 1976) 41 : E396-E402, 2016

6. Jenkins LA, Capen DA, Zigler JE, Nelson RW, Nagelberg S : Cervical spine fusions for trauma. A long-term radiographic and clinical evaluation. Orthop Rev Suppl : 13-19, 1994

7. Kawakami M, Tamaki T, Yoshida M, Hayashi N, Ando M, Yamada H : Axial symptoms and cervical alignments after cervical anterior spinal fusion for patients with cervical myelopathy. J Spinal Disord 12 : 50-56, 1999

8. Kim HJ, Choi BW, Park J, Pesenti S, Lafage V : Anterior cervical discectomy and fusion can restore cervical sagittal alignment in degenerative cervical disease. Eur J Orthop Surg Traumatol 29 : 767-774, 2019

9. Kim JH, Park JY, Yi S, Kim KH, Kuh SU, Chin DK, et al. : Anterior cervical discectomy and fusion alters whole-spine sagittal alignment. Yonsei Med J 56 : 1060-1070, 2015

10. Kim JT, Lee HJ, Choi DY, Shin MH, Hong JT : Sequential alignment change of the cervical spine after anterior cervical discectomy and fusion in the lower cervical spine. Eur Spine J 25 : 2223-2232, 2016

11. Kwon WK, Kim PS, Ahn SY, Song JY, Kim JH, Park YK, et al. : Analysis of associating factors with C2-7 sagittal vertical axis after two-level anterior cervical fusion: comparison between plate augmentation and standalone cages. Spine (Phila Pa 1976) 42 : 318-325, 2017

12. Lan Z, Huang Y, Xu W : Relationship between T1 slope minus C2-7 lordosis and cervical alignment parameters after adjacent 2-level anterior cervical diskectomy and fusion of lower cervical spine. World Neurosurg 122 : e1195-e1201, 2019

13. Lau D, DiGiorgio AM, Chan AK, Dalle Ore CL, Virk MS, Chou D, et al. : Applicability of cervical sagittal vertical axis, cervical lordosis, and T1 slope on pain and disability outcomes after anterior cervical discectomy and fusion in patients without deformity. J Neurosurg Spine 18 : 1-8,
2019

14. Lee HJ, Kim JH, Kim IS, Hong JT : Physiologic cervical alignment change between whole spine radiographs and normal standing cervical radiographs. World Neurosurg 122 : e1222-e1227, 2019

15. Lee SH, Son ES, Seo EM, Suk KS, Kim KT : Factors determining cervical spine sagittal balance in asymptomatic adults: correlation with spinopelvic balance and thoracic inlet alignment. Spine J 15 : 705-712, 2015

16. Ling FP, Chevillotte T, Leglise A, Thompson W, Bouthors C, Le Huec JC : Which parameters are relevant in sagittal balance analysis of the cervical spine? A literature review. Eur Spine J 27 : 8-15, 2018

17. Naderi S, Ozgen S, Pamir MN, Ozek MM, Erzen C : Cervical spondylotic myelopathy: surgical results and factors affecting prognosis. Neurosurgery 43 : 43-49, discussion 49-50, 1998

18. Oe S, Togawa D, Nakai K, Yamada T, Arima H, Banno T, et al. : The influence of age and sex on cervical spinal alignment among volunteers aged over 50. Spine (Phila Pa 1976) 40 : 1487-1494, 2015

19. Smith JS, Shaffrey Cl, Lafage V, Blondel B, Schwab F, Hostin R, et al. : Spontaneous improvement of cervical alignment after correction of global sagittal balance following pedicle subtraction osteotomy. J Neurosurg Spine $17: 300-307,2012$

20. Song KJ, Taghavi CE, Lee KB, Song JH, Eun JP : The efficacy of plate construct augmentation versus cage alone in anterior cervical fusion. Spine (Phila Pa 1976) 34 : 2886-2892, 2009

21. Staub BN, Lafage R, Kim HJ, Shaffrey $\mathrm{Cl}$, Mundis GM, Hostin R, et al. : Cervical mismatch: the normative value of $\mathrm{T} 1$ slope minus cervical lordosis and its ability to predict ideal cervical lordosis. J Neurosurg Spine $30: 31-37,2018$

22. Tamai K, Buser Z, Paholpak P, Sessumpun K, Nakamura H, Wang JC : Can $\mathrm{C7}$ slope substitute the T1 slope?: an analysis using cervical radiographs and kinematic MRls. Spine (Phila Pa 1976) 43 : 520-525, 2018

23. Tang JA, Scheer JK, Smith JS, Deviren V, Bess S, Hart RA, et al. : The impact of standing regional cervical sagittal alignment on outcomes in posterior cervical fusion surgery. Neurosurgery 76 Suppl 1 : S14-S21; discussion S21, 2015

24. Villavicencio AT, Babuska JM, Ashton A, Busch E, Roeca C, Nelson EL, et al. : Prospective, randomized, double-blind clinical study evaluating the correlation of clinical outcomes and cervical sagittal alignment. Neurosurgery 68 : 1309-1316; discussion 1316, 2011

25. Wang Q, Wang XT, Zhu L, Wei YX: Thoracic inlet parameters for degenerative cervical spondylolisthesis imaging measurement. Med Sci Monit 24 : 2025-2030, 2018

26. Weng C, Wang J, Tuchman A, Wang J, Fu C, Hsieh PC, et al. : Influence of $\mathrm{T} 1$ slope on the cervical sagittal balance in degenerative cervical spine: an analysis using kinematic MRI. Spine (Phila Pa 1976) 41 : 185-190, 2016 